\title{
MARIÀ MANENT I EL SENTIMENT DEL COSMOS (Notes sobre la influència oriental)
}

Enric BALAGUER Universitat d'Alacant

\begin{abstract}
"Va ser el poeta anglès John Langdon-Davies (...) qui em féu conèixer la poesia xinesa. Em va atreure de seguida la seva finor, la seva melangia, la seva delicada joia. Recordo un vespre de maig, a Ripoll, en què Langdon-Davies em va llegir poemes traduits per Waley. Feia una nit de lluna molt clara. Ja al llit, els versos en cantaven a la memòria. I sota la finestra de la meva cambra, en un rengle de pollancs, hi havia una tal densitat de rossinyols que el seu cant apassionat em produí un deliciós insomni"'.

Aixf relata Marià Manent el seu encontre amb el món oriental. Un encontre fructffer amb germinacions de tota mena i amb múltiples resultats. D'entre els quals cal destacar tres antologies de versions de poesia xinesa: L'aire daurat ${ }^{2}$ (1928) i Com un núvol lleuger ${ }^{3}$ (1967), Vell pats natal de Wang Wei ${ }^{4}$ (1986). Les versions de poesia de Marià Manent mostren una compenetració amb el pensament oriental intensa $\mathrm{i}$ transparent. A les traduccions poètiques cal afegir les de la prosa, ja que el poeta traduí diverses obres de Kipling, un autor ben significatiu, per altra part.
\end{abstract}

${ }^{1}$ Lluís Busquets, Plomes catalanes contemporànies, Barcelona, Ed. El Mall, 1981, p.32.

${ }^{2}$ Barcelona, Proa, 1986, $4^{\mathrm{a}}$ edic.

${ }^{3}$ Barcelona, Proa, 1985, $2^{\mathrm{a}}$ edic.

${ }^{4}$ Barcelona, Empúries, amb col·laboració de M. Dolors Folch. 
Joan Teixidor malda per considerar les versions poètiques de Manent com a obres de creació de l'autor i no com a simples traduccions: "com sigui -diu Teixidor- creiem que cal fer la distinció entre Manent traduint poesia anglesa o Manent interpretant poesia xinesa"5. I una consideració, si fa no fa semblant, li mereix $L$ 'aire daurat a Palau i Fabre ${ }^{6}$.

Caldria tenir present les dificultats que entranya tota traducció poètica, i més encara tractant-se d'obres orientals extremament allunyades del nostre sistema lingüístic $\mathrm{i}$ realitzades ja sobre altres traduccions o versions. En aquest cas el paper del traductor assoleix una importància especialment significativa. La prova d'aquesta importància la podem fer en contrastar les diverses versions d'un mateix llibre. Palau i Fabre, en versionar textos del Tao te King, els presenta com una conjectura "no sols perque no són fetes directament sobre l'original xinès -ens diu l'autor- sinó perquè les traduccions directes que hem consultat difereixen considerablement l'una de l'altra"7. Hi ha en les versions un enorme marge de creació on emergeix la veu del subjecte traductor. Si aço és un fet habitual en les traduccions apareix d'una forma accentuada en els casos dels textos orientals com ho il.lustra el mateix Marià Manent (i M. Dolors Folch) en la traducció de Vell pats natal de Wang Wei, bo i mostrant el pas dels ideogrames a la versió, primer, no gramaticalitzada del text $\mathrm{i}$, després, gramaticalitzada $\mathrm{i}$ poetitzada.

Però més enllà de les traduccions, la presència oriental amera el conjunt de l'obra de Manent. La sintonia del poeta amb el saber oriental

5 A flor d'oblit, Barcelona, Ed. 62, 1986, p. 9. D'ara endavant ens hi referirem: F.O.

6 "Tant si es proposa de fer una traducció, una versió o una interpretació, el cert és que Marià Manent sap que, d'una manera o d'una altra, el resultat que ha d'obtenir ha de ser implancablementel d'una obra d'art. I, ¿perquè una obra d'art no podria ser feta a través d'una altra obra d'art com a partir d'una emoció o d'un paisatge? Jo crec, continuo creient que Marià Manent, a causa d'aquesta extremada voluntat artística que li és inherent, assoleix, a voltes, a través de la traducció-versió-interpretació, la creativitat", "Apunt sobre la poètica de Marià Manent" a Quaderns inèdits de l'Alquimista, Barcelona, Ed. 62, 1991, p. 99-100.

${ }^{7}$ Lao-Tze, Tao-te-king, Barcelona, 1965, p. 7. 
abasta esferes i aspectes molts diversos, des de concepcions filosòfiques fins a recursos estètics. No és un perfum que s'esvaeix com una aquarel.la. Per poc que llegim la seua obra poètica o part de la seua prosa de dietaris, ens trobem amb una sensibilitat especial: delicadesa, sentiment del temps, connexió amb la natura, atenció als detalls més quotidians, refinament, disposicio contemplativa, serenitat i ritme reposat, estima pel silenci... Pels qui creuen en la reencarnació és ben facil pensar que Manent, en molts moments, és un poeta oriental reencarnat a Catalunya.

Dels múltiples aspectes que podríem tractar, com ara la idea de canvi de la natura, concepcions poètiques que entronquen amb l'univers oriental, etc. hem triat el sentiment cosmic. El poeta, sobretot en els seus dietaris, és un ésser lliurat a la contemplació, amb una atenció per la natura, en molts moments, parangonable amb el sentiment d'interioritat oriental. La natura s'observa des de l'atenció plaentera, sense fer-ne cap símbol ni buscar altres missatges que no siga el de reflectir un encontre ple d'energies. Vegem una de les anotacions d'A flor d'oblit triada a l'atzar:

Hem anat fins al peu de les Roques de Bona Vista. Es domina tota la línia del Pirineu: el Puigmal al mig, el Canigó a la dreta. Sota el cel -glauc i taronja pàl.lid -la muntanya semblava, retalladíssima, un vidre glaçat. Els castanyers florits traspuaven vora nostre un incendi delicat, que els comunicava com una vida fantàstica. (FO:50)

Hom diu que mentre a Occident l'home és en la natura, l'oriental proclama que l'home és la natura. No hi ha diferència ni frontera entre el subjecte i el món. Però deixem que ho explique el mateix poeta. En la introducció al Vell pats natal de Wang Wei, M. Dolors Folch fa aquest comentari sobre el poeta xinés i la seu relació amb la naturalesa:

Aquesta actitud (...) davant de la naturalesa el connecta clarament amb el taoisme i el budisme, que estimula una contemplació atenta i humil de la natura per arribar a assolir la calma, el distanciament $i$ la puresa que caracteritzen una ment il.luminada. Wang Wei mira el paisatge amb total passivitat, sense cap intenció de veure-hi res, registrant simplement i sense ordenar el que entra en els seu camp visual, reflectint la naturalesa sense parcialitat ni prejudicis, com en un mirall, símbol predilecte de la literatura taoista i budista. En aquesta natura, els 
signes de la presència humana no es busquen deliberadament ni s'exclouen sistemàticament, i la seva obra no conté cap comentari sobre la relació entre l'home i la naturalesa, bàsicament perquè no parteix de la premissa que hi hagi cap distinció entre ambdues. En aquest sentit, és l'antítesi d'una aproximació romàntica a la naturalesa. Conscient de formar-ne part integrant, és sensible sobretot a la seva harmonia: els seues sentiments no són mai els d'exaltació, sinó els d'una intensa pau. L'home, quan hi apareix $-i$ no ho fa mai en actitud arrogant, sinó recolzat en un bastó o en una porta, o bé assegut-, és tractat en el mateix peu d'igualtat que els fenòmens nimis ${ }^{8}$.

En llegir aquest comentari podríem pensar que parla de la concepció de M. Manent tant com de la de Wang Wei. Per a comprovar-ho sols hem de reproduir qualsevol fragment sobre la natura, centrals en els seus dietaris. La natura no és portadora de cap signe específic ni és un espai contagiós de cap cosa si no és de calma i de permanència. La natura és vista quasi amb l'equanimitat d'un mateix. Quan descriu successos, ho fa amb parsimonia i mansuetud, no perquè aquests comporten cap significat -el significat interessa molt poc- sinó simplement perquè "són", "estan" ,"es viuen". L'anotació del 12 d'abril de 1938 d'El vel de maia conté el següent:

A primera hora de la tarda ba nevat una mica. Hi ha una grisor densa al Montseny i també cap al nord. Fa pocs dies registrava al dietari una joiosa nevada de flors de perera, i ara tornem a veure la neu autèntica de l'hivern, que es lliga tan bé amb els avets i el foc de l'estufa. Però no: no era una neu primaveral, breu $i$ indecisa. A mitja tarda a sortit el sol, que encén el verd daurat de les pollancredes, hi sento un cucut llunyà. A recs brillava l'aigua encesa'.

Sovint trobem en la natura un espai obert als ressons i a les sensacions més diverses formant part d'un conjunt que no oblida atorgar el protagonisme a les muntanyes 0 als pollancres o a les fulles o a la terra eixuta o gelada, glaçada o gebrada. L'expressió nítida de l'autor sembla acomplir l'objectiu de traslladar-nos aqueix aire de nuesa propi de l'esguard oriental, on s'atorga tanta importància a les grans coses com

${ }^{8}$ Op. Cit., p. 24.

${ }^{9}$ Barcelona, Ed. Destino i Ed. 62, 1985, p. 193. Ens hi referirem, d'ara endavant, amb les sigles VM. 
a les petites de l'entorn, en un univers que situa l'home a l'altura de les plantes o de la terra. Un text de de Sang-t'san, (japonés del segle VII) ens ve a dir el mateix:

Les coses infinitament petites són tan enormes

com les coses enormes poden ser-ho,

Doncs aquí no subsisteixen condicions externes;

Les coses infinitament enormes són tan petites

com les coses petites poden ser-ho,

Doncs aquí, els límits objectius no es consideren ${ }^{10}$.

El zen aborda els diversos estats de reflex de la natura des d'un distinció entre el sabi -la percepció de quietud, soledat, percepció de bellesa- i el wabi -percepció d'intensitat de una cosa en contrast amb el buit de cadascú. Als quals s'afegeix el awarre -tristesa compassiva de l'efímer bell- $\mathrm{i}$ el yugen -visió súbita d'alguna cosa misteriosa $\mathrm{i}$ inexplicable, molt frequient en el teatre No- tot integrant els quatre estats d'ànim fonamentals en el furyu, l'atmosfera general del gust zen. Ben sovint trobem aquests quatre en la prosa de Manent. El curt espai de què disposem ens impedeix fer una antologia completa:

Quina collita tràgica en aquests breus instants! Semblava una realitat absurda davant del paisatge tranquil, amable, daurat, de la tardor. Però la mort ens volta, ens sotja, ens parla amb la veu estranya i dura. (VM: 143)

Dia pur, tranquil, paradisíac, amb nuvolets blancs al cim del Montseny. Quina calma, quins arbres translúcids de cristall, quins alegres pinsans xiulant al bell cim de les alzines! No em moc de casa. Contemplo les fagedes torrades, el cel pur, les grives i merles que passen cap a uns raïms tardans. Es un dels dies de tardor més estàtics, més daurats i més purs que recordo. (VM:139)

El dietari El vel de maia recull l'experiència del poeta durant els tres anys de guerra. El desencadenament bèllic va portar el poeta a estar en contacte amb la natura i paradoxalment visqué entre dos punts intensos $\mathrm{i}$ oposats aquests tràgics anys: "La guerra, aquesta infeccio

${ }^{10}$ D.T.Suzuki, Manual de budismo zen, Buenos Aires, Kier, 1976, p. 80. La traducció al català és nostra. 
horrible, m'ha portat a un món de pau i d'idil-li on mai no m'havia estat possible de viure tant de temps. Un extrem d'angoixa i de tragèdia m'ha dut a un extrem d'oasi i de quietud"(VM:69). El poeta va viure aquesta experiència d'extrems i la va exposar tal com la sentiria i l'acceptaria un oriental avesat a conviure integrant les contradiccions. El títol de l'obra recorda com el poeta viu aquest encontre amb la natura com un veritable "vel de maia", com un filtre d'il·lusió més que no pas de realitat. Per un altre costat, l'escenificació d'extrems: pau i sang, tranquil-litat i desesperació, assossec i tragèdia, l'autor la viu amb l'esperit d'un oriental.

El sentiment del temps és una altre dels elements a comentar de l'obra de Manent, per tal com està lligat, molt sovint, amb les sensacions de la natura. La primera motivació, revelada per l'autor, en escriure dietaris com $A$ flor d'oblit és la lluita contra el pas del temps, "obsedit per la voracitat del temps que tot ho esborra" (FO:17). En un altre moment confessa: "el temps se'ns enduu; la vida sembla, alhora llarga i brevíssima. Quants continents del meu passat dormen ja en l'oblit! Només en queden petxines apagades, brins d'herba seca..." (Ibid.).

Al pròleg de L'aroma d'arç ens comunica que "aquestes notes disperses, almenys per al meu ús personal, em semblen com petites zones salvades de la marea del temps i de la inexorable erosió de la memòria" ${ }^{11}$. Els dietaris com una forma d'aturar el temps; en fixar escenes, moments viscuts, pensaments, records, instants... els eternitza i els salva de la voracitat del temps. Com tota escriptura, esdevé una forma de transcendir la mort. Davant de l'anorreament, del final, l'escriptura permet sentir el temps congelat.

Un dels mecanismes de l'autor per anorrear la sensació devastadora del pas del temps és buscar l'instant privilegiat que permet superar la monotonia $i$ que, en establir ple contacte amb allo observat, ve a ser com sentir un instant d'eternitat: la contemplació permet fondre l'ésser amb el món.

${ }^{11}$ Barcelona, Laertes, 1982, pp. 9-10. 
3 de juliol. Hem anat fins al peu de les Roques de Bona Vista. Es domina tota la línia del Pirineu: el Puigmal al mig, el Canigó a la dreta. Sota el cel -glauc i taronja pàl-lid -la muntanya semblava, retalladíssima, un vidre glaçat. Els castanyers florits traspuaven vora nostre un incendi delicat, que els comunicava com una vida fantàstica. Era un capvespre immòbil i pur. (FO:50)

Manent, a través dels moments de contemplació, es fon amb les coses, perd consciencia de si mateix i se sostrau del pas del temps. Quan torna a casa $\mathrm{i}$ escriu aço al dietari tornarà a reviure aquesta sensació: una segona superació del temps. El temps per a Manent, segons ha observat Sam Abrams ${ }^{12}$, sembla dividir-se en dos classes: el temps normal -profa- $i$ el temps sagrat o sacralitzat, quan la contemplació assoleix l'estat de compenetració absoluta. El temps sagrat el conformen moments elevats a una condició de solemnitat íntima, però no perquè allo observat trasllade sensacions impressionants o escenes força tel-lúriques, ans al contrari, perque en focalitzar qualsevol cosa amb parsimonia i afectivitat aquesta rep una consideracio equivalent a la resta de la creació de l'univers. El centre de l'univers, per als orientals, es localitza en tots els aspectes de la vida.

Parlant de Sant Joan de la Creu, el poeta escriu:

Brilla en ell, com en pocs, el misteri poètic: aquesta rara confluència del llenguatge, les coses $\mathrm{i}$ el cor de l'home, la fusió meravellosa de la música, l'ànima i el cor, de la coses moridores i l'eternitat. (FO:62)

L'arribada a un estat de conjunció en què es copsa allo moridor i allo etern, és un estat anímic concret que supera els encotillaments de la percepció convencional. Tastar l'eternitat, el sentiment d'eternitat i també la caducitat, la mort, és una forma de traspassar la sensació restringida de mancança; la conjunció entre el llenguatge, les coses i el cor de l'home n'és la forma.

Quan M. Dolors Folch parla de la poètica de Wang Wei ens diu que el poeta xinés era partidari de la senzillesa expressiva: "La intuïció subtil s'ha de transmetre en poques paraules" ${ }^{13}$. Podria ser un rotund

12 "El Dietari" a AA.DD., Marià Manent, Barcelona, I.C.E., 1989, p. 31.

${ }^{13}$ Op. cit., p. 25. 
enunciat del mateix Manent tot parlant de la seua concepció poètica. Aquesta simplicitat que unifica transparència i elegància, trasllada una sensació de puresa primigènia i una sensació d'incardinació còsmica de forma ben eficaç. Més que un torsimany, tenim un fotògraf, més que un impressionista que busca efectes espectaculars un contemplador sensual però fidel.

En molt moments, la forma de copsar aquest instant és a través d'una evocació mínima, d'una imatge. La prosa de dietaris com $\mathrm{El}$ vel de maia, molt sovint, sembla construïda amb pedaços de haikus, l'anotació del 12 d'abril de 1938 acaba,

A mitja tarda torna a sortir el sol, que encén el verd daurat de les pollancredes, i sento un cucut llunyà. Als recs brillava l'aigua encesa. (VM:193)

I la del 16 d'abril acaba amb una frase que ens permetem presentarla amb la disposició estròfica d'un haikus:

El sègol ja és ben alt

(i) s'hi destaca el rosa pàl·lid

de les pomeres en flor. (VM:194)

La textura del microcosmos poètic de Manent sembla desembocar en l'expressió concisa que recull l'instant il/luminat (satori) en què hom pren consciència de les coses, canta, evoca, sent: allò que estava dispers s'hi ajunta, el que semblava ser un element insignificant pren relleu, un moment en què tot és un eco de tot. L'economia expressiva, l'aparent insignificància, la reducció el-líptica són elements que engrandeixen de sobte un petit gest, l'olor d'una planta, l'estat d'un núvol. Com diu Kakuzo al seu meravellós Llibre del te: "La perfecció és arreu; només cal que ens preocupem de descobrir-la". William Blake, pel seu costat, havia mostrat una idea ben proxima quan escriu: "If the doors of perception were cleansed every thing/ would appear to man as it is, infinite": "Si les portes de la percepció es purificassen cada cosa apareixeria a l'home com és, infinita".

En la poesia de Marià Manent trobem una atenció envers l'entorn quotidia que fa de cada sensació, de cada idea, de cada encontre, un descobriment rellevant, un acte de solemnitat íntima. Com per als autors 
orientals, per a Manent, la vida quotidiana no necessita ser transcendent per tenir profunditat, car aqueix sentiment apareix en l'experiència l'ordinària.

Hi ha en l'obra de Manent una evocació constant al silenci, un silenci altament preuat $\mathbf{i}$ que no sols evoca sinó que posa en pràctica. "Marià Manent -ens diu Palau i Fabre- és l'únic que ha sabut obeir tan bé la veu interior que ha preferit emmudir abans de fer literatura"14. Avesats com estem a veure la prolixitat de produccio, el volum de poesia completa de l'autor amb 128 pàgines n'és tot un cas excepcional. Per als orientals dir les coses completament imprescindibles (i fer-ne silenci de la resta) és una exigència. Amb la necessitat de silenci, amb l'apologia del silenci, explícitament $\mathrm{i}$ implicita, trobem un altre dels ponts que uneixen el nostre poeta amb el món oriental.

14 "L'obra de Marià Manent tocada pel silenci" a Ariel, núm. 19, (juny) 1950, p. 19. 